\title{
Silane crosslinking of poly(lactic acid): The effect of simultaneous hydrolytic degradation
}

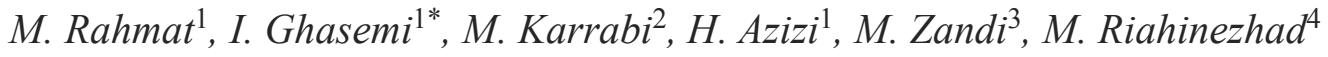 \\ ${ }^{1}$ Department of Plastics, Iran Polymer and Petrochemical Institute, P.O. Box: 14965/115 Tehran, Iran \\ ${ }^{2}$ Department of Rubber, Iran Polymer and Petrochemical Institute, P.O. Box: 14965/115 Tehran, Iran \\ ${ }^{3}$ Department of Biomaterial, Iran Polymer and Petrochemical Institute, P.O. Box: 14965/115 Tehran, Iran \\ ${ }^{4}$ Department of Chemical Engineering, Institute for Polymer Research, University of Waterloo, ON N2L 3G1 Waterloo, \\ Canada
}

\begin{abstract}
In this work, silane crosslinking of poly (lactic acid) (PLA) was studied. PLA was grafted with vinyltrimethoxysilane (VTMO) via melt mixing in an internal mixer, followed by a crosslinking reaction in hot water for different times. The effect of simultaneous hydrolytic degradation in hot water $\left(70^{\circ} \mathrm{C}\right)$ during crosslinking was monitored. Silane grafting of PLA was characterized using mixing torque and gel permeation chromatography (GPC) analysis. The results revealed that by increasing the silane $(0-7 \mathrm{wt} \%)$ and peroxide $(0-0.5 \mathrm{wt} \%)$ contents, the degree of grafting was increased. A peak corresponding to higher molecular weight in GPC chromatograms appeared in comparison to pure PLA due to the grafting reaction. Gel content, swelling test, GPC and thermal gravimetric analysis (TGA) were performed to monitor gel structure and concurrent hydrolytic degradation. Results confirmed that the occurrence of hydrolytic degradation during crosslinking and gel content of some samples tended to zero over $10 \mathrm{hr}$ of immersion in hot water. The effect of hydrolytic degradation was not significant up to $10 \mathrm{hr}$ and a tight gel structure was obtained. However, at longer crosslinking times, hydrolytic degradation was the dominant mechanism that leads to network defects.
\end{abstract}

Keywords: biodegradable polymers, crosslinking, hydrolytic degradation, poly(lactic acid), silane grafting

\section{Introduction}

Recently, poly(lactic acid) (PLA) has been extensively considered by researchers as a suitable candidate to replace some synthetic polymers, due to its good mechanical properties, easy processability, low environmental impact and its renewable resources [13]. However, its thermal deformation around $60^{\circ} \mathrm{C}$, is an important limitation for some applications require higher temperatures e.g. using PLA in food packaging industry, bottles, medical products [4-6].

Crosslinking could be a good strategy to overcome this disadvantage. Radiation and chemical crosslinking are two well-known methods for osslinking and have been reported in the literatures [7-15].
During radiation crosslinking (electron beam and gamma irradiation), macromolecule radicals (in the presence of multifunctional monomers as triarylisocyanurate) are created in the solid state using high energy beams that produce linkages between the polymer chains. During chemical crosslinking, however, radicals are usually formed by a chemical agent. One of the most common crosslinking agents used in polyethylene are silane compounds [16]. There is a large body of reports on different features of silane crosslinking in polyethylene [17-19]. In this method, grafting of silane molecules is accomplished by peroxide radicals, and then linkages are formed in hot water via hydrolysis and condensation reactions.

\footnotetext{
${ }^{*}$ Corresponding author, e-mail: I.ghasemi@ippi.ac.ir

(C) BME-PT
} 
This method was applied to create crosslinked PLA by Han et al. [11]. In this study, vinyltrimethoxysilane (VTMO) and vinyltriethoxysilane (VTES) were used and the results showed that siloxane linkage were successfully formed and the thermal and mechanical properties were improved.

One of the limitations of this method for PLA is simultaneous hydrolytic degradation during the crosslinking in hot water [20]. The hydrolysis of PLA in aqueous media starts with the water diffusion between polymer chains in the amorphous phase which are less resistant to the penetration of water molecules, followed by hydrolytic splitting of the ester bonds [1, 21]. Four-stage model was proposed for hydrolytic degradation including diffusion of water, hydrolysis progress producing oligomers, migration and diffusion of the oligomers to the [22]. Effect of specimen's size [23], initial molecular weight [24], crystallinity [25, 26], medium temperature [27], and presence of nano particles [28] on hydrolytic degradation of PLA have been reported. According to literature, it can be concluded that the silane crosslinking may be affected by probable hydrolytic degradation.

The influence of crosslinking on degradability of PLA has been reported and the results indicated that enzyme was less effective towards crosslinked PLA than neat PLA. In other words, the deterioration of the biodegradability of PLA is affected by crosslinking due to reduction of enzyme diffusion in PLA $[11,29]$.

Södergård et al. [30] showed peroxide modifying of PLA with tert-butylperoxybenzoatein melt mixing. Their results suggested more rapid decrease of molecular weight during immersion in water, because of higher permeability for both water and oligomers.

In our group, peroxide crosslinking of PLA was studied before [15]. In this study, silane crosslinking and hydrolytic degradation of PLA was studied as two competitive reactions. Optimization for obtaining the suitable gel structure was the main target of this study followed by the balance between two reactions, crosslinking and hydrolytic degradation. Crosslinking reaction was evaluated using gel content and crosslink density while assessment of degradation was done by gel permeation chromatography (GPC) and thermogravimetric analysis (TGA). The silane and peroxide contents and immersion time were the variable parameters to adjust the formation of network via their effects on two aforesaid reactions.

\section{Experimental section \\ 2.1. Materials}

Poly(lactic acid), PLA, (IngeoBiopolymer 3251D) was purchased from Nature works LLC, with a melt flow index $30 \mathrm{~g} / 10 \mathrm{~min}\left(190^{\circ} \mathrm{C}, 2.16 \mathrm{~kg}\right)$ and a density of $1.24 \mathrm{~g} / \mathrm{cm}^{3}$. Vinyltrimethoxysilane, VTMO (YAC-V171, $\geq 98 \%$ purity) was supplied from Lanyachem and Dicumylperoxide, DCP, (99\% purity), obtained from Aldrich, Germany. Tetrahydrofuran, THF, and chloroform solvents were used for determination of gel content, degree of swelling and GPC experiments and were purchased from Merck (USA).

\subsection{Preparation of silane grafted PLA}

Silane grafting of PLA was accomplished via melt mixing in an internal mixer (Brabender, Germany). The temperature of mixing was $190^{\circ} \mathrm{C}$ and rotor speed was $75 \mathrm{rpm}$. At first, PLA was dried in an oven at $80^{\circ} \mathrm{C}$ for $8 \mathrm{hr}$ afterward it was added to mixing chamber and $30 \mathrm{~s}$ after complete melting, solution of DCP in VTMO was poured gradually by syringe (during the $30 \mathrm{~s}$ ). Mixing was continued for $5 \mathrm{~min}$ utes and the obtained compound was immediately compressed at $200^{\circ} \mathrm{C}$ in a hot press (Toyoseiki, Japan). To avoid premature crosslinking, PLA sheets were stored in desiccators after pressing. The sample and code formulations are depicted in Table 1. In these codes, the number after S denotes VTMO concentrations and the number after D corresponds to DCP contents. Crosslinking of silane grafted PLAs were done in hot water at $70^{\circ} \mathrm{C}$ for 1,10 and $20 \mathrm{hr}$. CP, as control sample, represents processed PLA in the same conditions.

Table 1. Sample names and compositions

\begin{tabular}{|l|c|c|c|}
\hline Sample name & $\begin{array}{c}\text { PLA } \\
\text { [phr] }\end{array}$ & $\begin{array}{c}\text { VTMO } \\
\text { [phr] }\end{array}$ & $\begin{array}{c}\text { DCP } \\
\text { [phr] }\end{array}$ \\
\hline CP & 100 & 0 & 0 \\
\hline S3 & 100 & 3 & 0 \\
\hline D3 & 100 & 0 & 0.3 \\
\hline S3D1 & 100 & 3 & 0.1 \\
\hline S3D3 & 100 & 3 & 0.3 \\
\hline S3D5 & 100 & 3 & 0.5 \\
\hline S5D1 & 100 & 5 & 0.1 \\
\hline S5D3 & 100 & 5 & 0.3 \\
\hline S5D5 & 100 & 5 & 0.5 \\
\hline S7D1 & 100 & 7 & 0.1 \\
\hline S7D3 & 100 & 7 & 0.3 \\
\hline S7D5 & 100 & 7 & 0.5 \\
\hline
\end{tabular}




\subsection{Methods}

The gel content of the crosslinked PLA was determined using the amount of insoluble material in chloroform after $48 \mathrm{hr}$. About $0.25 \mathrm{~g}$ of a crosslinked polymer was cut into small pieces and placed in a pre-weighed stainless steel finemesh. After the test, the samples were washed with chloroform and dried at room temperature. The gel fraction was calculated as shown in Equation (1):

$$
\text { Gel fraction }[\%]=\frac{M_{1}}{M_{0}} \cdot 100
$$

where $M_{0}$ and $M_{1}$ are the initial weight and residual dried gel content of the crosslinked polymer, respectively.

Degree of swelling $(D S)$ at equilibrium condition was measured by immersion of the samples in chloroform at room temperature for $48 \mathrm{hr}$, according to Equation (2):

$D S=1+\frac{\rho_{\text {polymer }}}{\rho_{\text {cloroform }}} \cdot\left(\frac{W_{\mathrm{s}}}{W_{\mathrm{p}}}\right)$

where $W_{\mathrm{s}}$ is the weight of solvent in the swollen network, $W_{\mathrm{p}}$ is the weight of dry gel component in the crosslinked PLA and $\rho_{\text {chloroform }}$ and $\rho_{\text {polymer }}$ are the specific densities of the solvent and the polymer, respectively.

The degree of swelling was used to measure the average molecular weight between crosslinks $\left(\bar{M}_{\mathrm{c}}\right)$. The swelling ratio decreases with increasing gel content and decreasing $\bar{M}_{\mathrm{c}}$. According to the theory of Flory and Rehner [31], $\bar{M}_{\mathrm{c}}$ is defined by Equation (3):

$$
\frac{1}{\bar{M}_{\mathrm{c}}}=\frac{2}{\bar{M}_{\mathrm{n}}}-\frac{\left(\frac{\bar{\nu}}{V_{1}}\right)\left[\ln \left(1-\frac{1}{D S}\right)+\frac{1}{D S}+\chi_{12}\left(\frac{1}{D S}\right)^{2}\right]}{\frac{1}{\sqrt[3]{D S}}-\frac{1}{2 D S}}
$$

where $\bar{v}$ is the specific volume of the polymer, $v_{2}$ is the volume fraction of the polymer in the swollen mass, $V_{1}$ is the molar volume of the solvent $\left(80 \mathrm{~cm}^{3} \cdot \mathrm{mol}^{-1}\right), \chi_{12}$ is the Flory solvent-polymer interaction parameter $(0.1$ as reported in the literature [11]), $\bar{M}_{\mathrm{n}}$ is the primary molecular mass, and $\bar{M}_{\mathrm{c}}$ is the average molecular mass between crosslinks.

The amount of crosslink bonds in a unit volume is known as the crosslink density $(v)$. The crosslink density is related to $\bar{M}_{\mathrm{c}}$ through Equation (4):

$$
v=\frac{\rho_{\mathrm{p}}}{\bar{M}_{\mathrm{c}}}
$$

where $\rho_{\mathrm{p}}$ is the density of the polymer.

The average molecular weight and molecular weight distribution of samples were determined using Gel Permeation Chromatography, GPC (Agilent 1100 series, USA) at $23^{\circ} \mathrm{C}$. Tetrahydrofuran (THF) was used as the carrier. Flow rate and injection volume were set at $1 \mathrm{~mL} \cdot \mathrm{min}^{-1}$ and $20 \mu \mathrm{L}$, respectively. GPC analysis was only conducted for the sol fraction of the polymer. The sol fraction of samples was extracted using chloroform for $48 \mathrm{hr}$ at room temperature, followed by drying at room temperature and dissolving in THF for chromatography test.

Since the microstructure of silane grafted PLA affects the hydrodynamic volume of the polymer, GPC results give us valuable information on the molecular weight of the modified polymer, in order to evaluate the grafting reaction.

The thermal degradation behavior of the crosslinked PLA was studied by Thermogravimetric Analysis, TGA, (STA 1640, UK). The test was carried out in nitrogen gas atmosphere within a range of $25-60^{\circ} \mathrm{C}$ at a heating rate of $10 \mathrm{C} / \mathrm{min}$.

\section{Results and discussion}

The mixing torque in internal mixer is affected by grafting reaction and can be used as an indicator for tracking of the reaction. The mixing torque versus time is demonstrated for all the samples in Figure 1. As can be seen in the Figure, the torque increased for the samples containing VTMO/ DCP solution in comparison to pure PLA and PLA containing VTMO

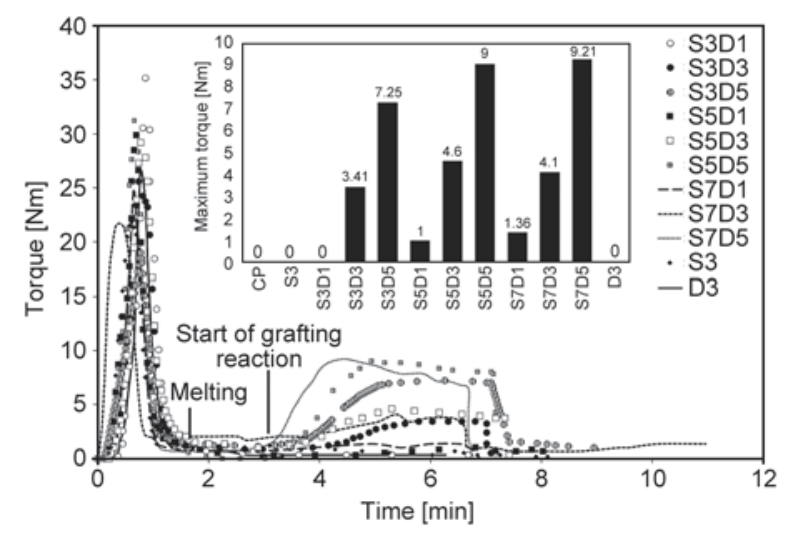

Figure 1. Mixing torque of PLA-silane grafting reaction. The Chart inside the Figure shows maximum torque of the grafting reaction mixing. 
and DCP. This behavior may be attributed to the grafting reaction. In other words, grafting reaction caused higher molecular weight and consequently higher viscosity. A gradual reduction of torque during grafting is observed which is related to thermal degradation of PLA in melt mixing process. The sample S7D5 (containing 5 phr DCP and 7 phr VTMO) showed the highest torque which implies to the highest grafting reaction for the sample. On the other hand, there is no considerable increment in torque for some samples including small amount of DCP which indicates to the main and effective role of peroxide in grafting reaction. Similar observation were reported for silane grafting of polyethylene [18] and polypropylene [32].

FTIR spectrum is usually used to confirm the grafting reaction by forming new peaks at $2843 \mathrm{~cm}^{-1}$ ( $\mathrm{Si}-\mathrm{OCH}_{3}$ bond). In our study, this bond was not clearly observed (spectrum is not shown here). Therefore the grafting reaction was monitored by gel content after crosslinking. It is well known that the gel fraction of the samples is formed by the hydrolysis and condensation of grafted silane in hot water.

The gel contents of the samples at different immersion times in hot water are shown in Figure 2. No gel content was obtained for the samples including silane and peroxide individually (S3 and D3), which indicates no grafting and crosslinking reactions occurred in these samples. This is in agreement with the results from Figure 1. It was expected for the sample including silane but for the samples with peroxide there are a contradictory reports. For example, occurrence of crosslinking with peroxide has been reported by Nijenhuis et al. [33], while Södergåd et

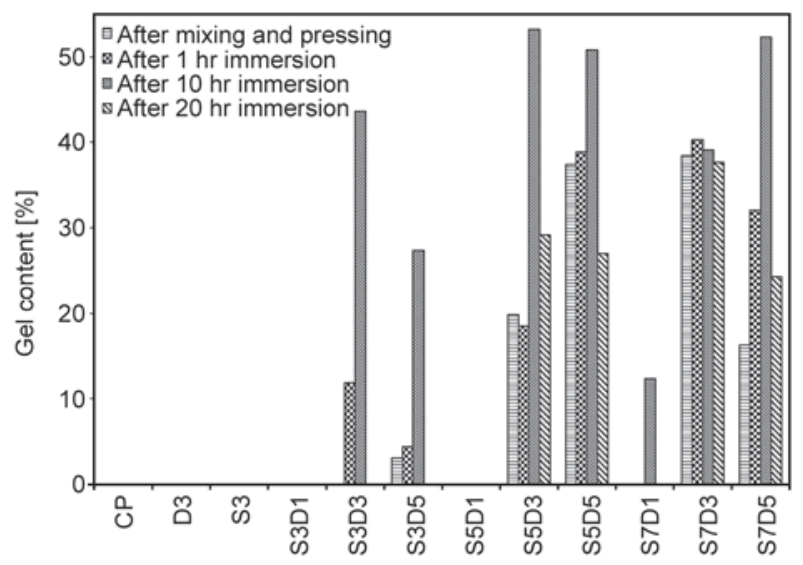

Figure 2. Gel content of samples at different curing condition, 1, 10 and $20 \mathrm{hr}$ after immersion in hot water compared to the sample with no immersion in water $a l$. [30] did not find any crosslinking in this case. In addition, in the samples containing DCP/VTMO solution with $0.1 \% \mathrm{DCP}$, no gel content was observed even at long immersion time. It seems that a low concentration of DCP cannot generate adequate radicals for grafting reaction and further crosslinking. It is found that having higher DCP contents in the samples improves the gel content.

As indicated in Figure 2, the variation of gel content versus immersion time passes through a maximum at $10 \mathrm{hr}$. The gel content is balanced by crosslinking and hydrolytic degradation. Below $10 \mathrm{hr}$ of immersion, the crosslinking is the predominant mechanism, while after that the chain scission in the presence of water becomes predominant. In other words, at long immersion times, the breakage of polymeric chains caused destruction of network into very small fragments which can exit from the finemesh stained steel in gel content experiments. Maximum gel fraction is found about $53 \%$ after $10 \mathrm{hr}$ for S5D3 sample.

Another interesting point in Figure 2 is the existence of gel content in the samples S5D3, S5D5, S7D3, and S7D5 with high silane concentration without immersing in hot water. The high potential of crosslinking due to high degree of grafting in these samples lead to easy crosslinking with atmospheric humidity during mixing and pressing steps.

To get a better insight of silane crosslinking of PLA, the degree of swelling was also determined. It is well known that the degree of swelling is related to the crosslink density where a low degree of swelling indicates a high crosslink density of polymer [14]. The degree of swelling, $\bar{M}_{\mathrm{c}}$ and crosslink density for three selected samples are presented in Table 2. As can be seen from the Table, sample S5D3 showed the lowest degree of swelling and higher crosslink density, because of higher silane content. The degree of swelling is commonly used to determine the average molecular weight between linkages. As expected, with a reduction in $\bar{M}_{\mathrm{c}}$, crosslink density goes up. This trend as a function of the aforesaid parameters was found for the other samples too.

Table 2. Degree of swelling, $\bar{M}_{\mathrm{c}}$ and crosslink density of selected samples immersed in hot water for $10 \mathrm{hr}$

\begin{tabular}{|l|c|c|c|}
\hline & DS & $\begin{array}{c}\overline{\boldsymbol{M}}_{\mathbf{c}} \\
{[\mathbf{g} / \mathbf{m o l}]}\end{array}$ & $\begin{array}{c}\text { v } \\
{\left[\mathbf{1 0}^{-4} \mathbf{~} \mathbf{~ m o l} / \mathbf{L}\right]}\end{array}$ \\
\hline S3D3 & 40.17 & 1873.89 & 6.62 \\
\hline S3D5 & 42.80 & 1953.02 & 6.35 \\
\hline S5D3 & 27.11 & 1445.68 & 8.58 \\
\hline
\end{tabular}




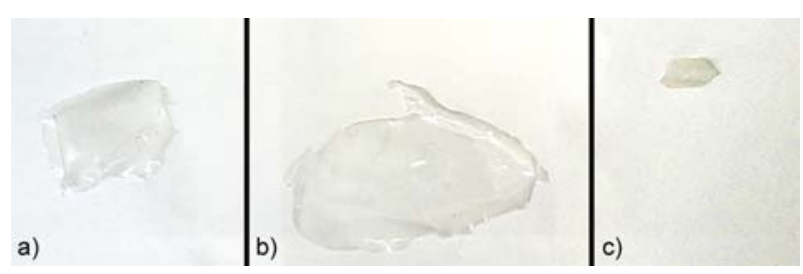

Figure 3. Dimension reversibility after $48 \mathrm{hr}$ swelling in chloroform at room temperature, S3D3 (a), S3D5 (b), S5D3 (c). Original dimensions of all samples were similar before swelling.

The variation in crosslink density of the samples was also confirmed by visual inspection. Figure 3 illustrates the physical shape of the crosslinked samples after swelling in chloroform and further drying. Because of chemical network formation, after evaporation of solvent, sample should go back to the original dimension in case of defect-free network. The original dimension after drying of swollen samples was obtained for sample S5D3 which implies perfect network structure. In other samples, $\bar{M}_{\mathrm{c}}$ is higher and longer distance between linkages is not able to return the polymeric chains in to their position before swelling. This phenomenon is schematically illustrated in Figure 3.

Schematic illustration of dimension reversibility is shown in Figure 4. As shown in Figure 4, having more silane grafted on polymer chains, makes the formed gel network tighter, in contrast to the low silane grafted PLA which had fewer linkages and consequently looser network. In addition, hydrolytic degradation leads to more defects in the network structure which caused the reduction of reversibility. To monitor the hydrolytic degradation of the samples during crosslinking in hot water, molecular weight and molecular weight distribution of the samples were measured using GPC. GPC chromatograms of pure PLA, silane grafted samples, and sol fraction of crosslinked samples (at 10, $20 \mathrm{hr}$ ) are presented in Figures 5-7.

The GPC curves in Figure 5 shows a meaningful difference between pure PLA and grafted samples which means grafting reaction has changed the molecular structure of PLA. A shoulder appeared at high molecular weight position, which can be attributed to the formation of higher molecular weight chains due to grafting reaction. It is worth noting that the peak of shoulder displays approximately 4 times higher molecular weight in comparison to pure PLA. This shoulder in GPC curve can be considered to the formation of short and long branching structures [34]. As can be seen in Figure 6, a new shoulder appeared at low molecular weight position after $10 \mathrm{hr}$ immersion in hot water. This shoulder can be an indication of the hydrolytic degradation during crosslinking. It can be noticed that the intensity of high molecular weight shoulder has been reduced compared to Figure 5. It is due to more contribution of these grafted chains in crosslinking reaction and formation of network. In other words, the grafted chains with higher molecular weight are involved in the crosslinking reaction and do not appear in the sol fraction.

By increasing the crosslinking time to $20 \mathrm{hr}$, the molecular weight shoulder completely disappeared and molecular weight distributions were shifted to lower molecular weights. It has been reported by Pistner et al. [35], at longer hydrolytic degradation time, bimodal and even multimodal curves are seen as result of selective degradation of the amorphous regions in GPC curve. In our study, only CP sample showed bimodal curves after $20 \mathrm{hr}$ immersion in hot water, while the other samples showed monomodal peak until $20 \mathrm{hr}$. It seems that the hydrolytic

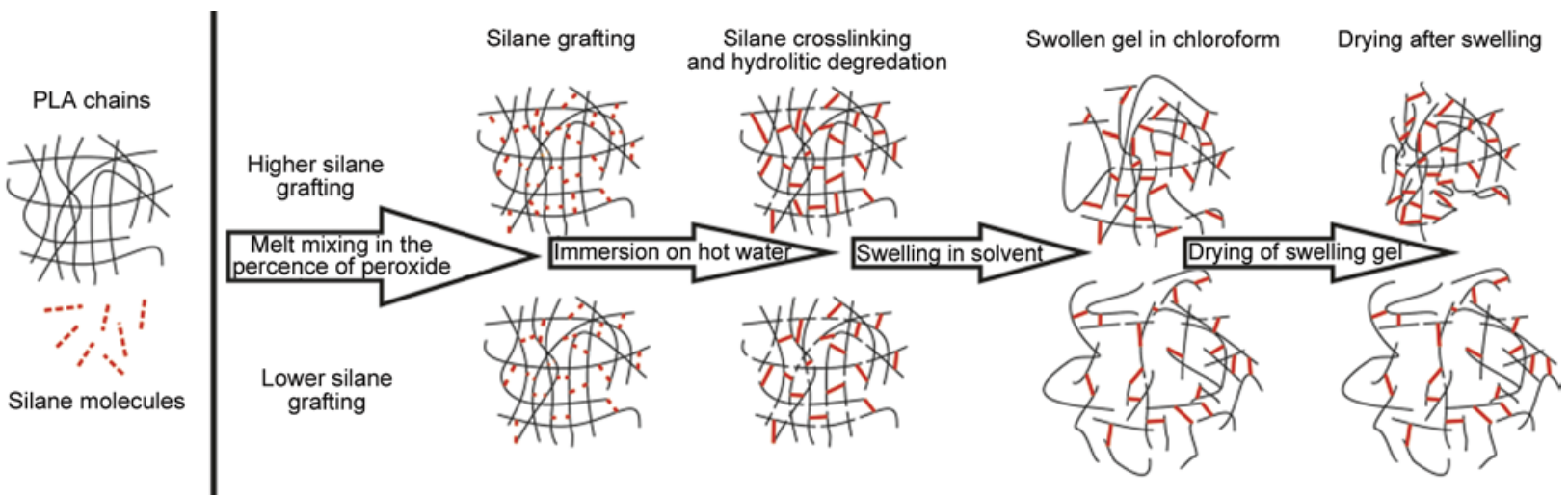

Figure 4. Schematic of dimensional reversibility of different gel network after swelling in solvent. Top way shows tight network with high dimensional reversibility and down way shows lose network that couldn't back to original dimension after swelling. 


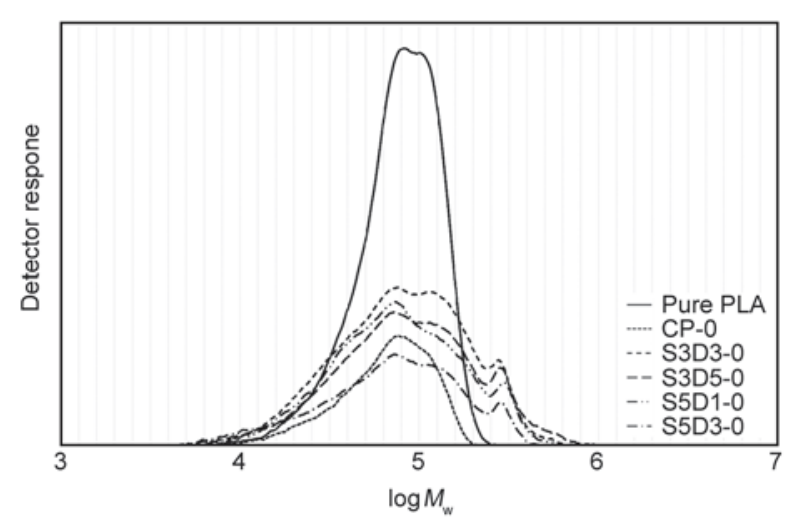

Figure 5. Molecular weight distribution of silane grafted PLAs compared with ungrafted samples (number after sample name shows time [hr] of immersing in hot water)

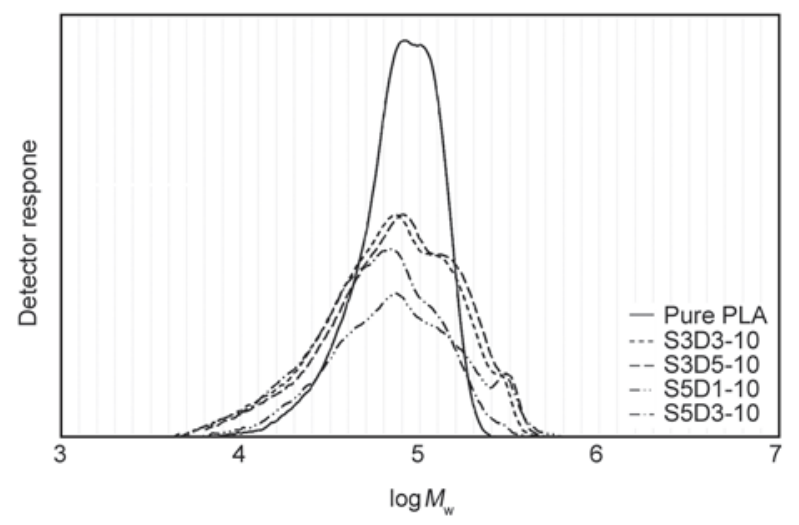

Figure 6. Molecular weight distribution of silane grafted PLAs after immersion in hot compared with ungrafted samples (number after sample name shows time [hr] of immersing in hot water)

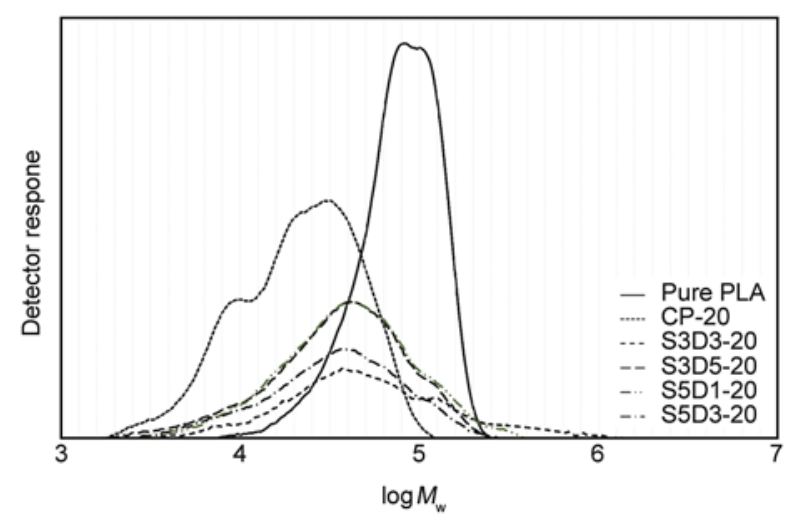

Figure 7. Molecular weight distribution of silane grafted PLAs after immersion in hot compared with ungrafted samples (number after sample name shows time [hr] of immersing in hot water)

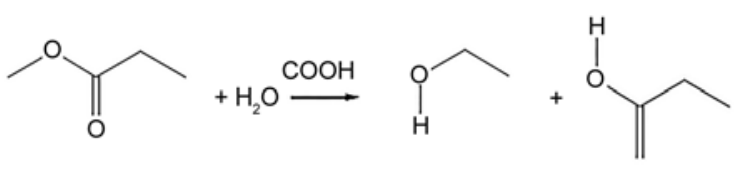

Figure 8. Mechanism of PLA ester bonds hydrolysis degradation mechanism is affected by silane grafting, through changing molecular structure and crystalline domains.

The proposed mechanism of hydrolytic degradation of PLA is shown in Figure 8 which indicates the final product of hydrolyzation is lactic acid [3]. It is believed that the hydrolytic degradation of PLA chains favorably occurred in the amorphous regions. The result of chain scission is the formation of lactic acid oligomers which can be a catalyst for more hydrolytic degradation, because of the abundance of carboxylic acid end groups in the reaction media. It is known that PLA degradation is an auto-catalytic reaction [24].

In first step of degradation, assuming slight degree of chain scission, the hydrolysis rate of the ester linkages can be modeled by Equation (5):

$\frac{1}{\bar{M}_{\mathrm{n}_{\mathrm{t}}}}=\frac{1}{\bar{M}_{\mathrm{n}_{0}}}-k_{1} t$

where $\bar{M}_{\mathrm{n}_{\mathrm{t}}}$ is the molecular weight at time $t, \bar{M}_{\mathrm{n}_{0}}$ is the $M_{\mathrm{n}}$ at $t=0$ without chain scission, $k_{1}$ is the general hydrolytic degradation rate constant and $t$ is the degradation time.

Taking into account the autocatalytic reaction, Equation (5) changes to Equation (6):

$\ln \frac{\bar{M}_{\mathrm{n}_{\mathrm{t}}}}{\bar{M}_{\mathrm{n}_{0}}}=-k_{2} t$

where $k_{2}$ is the rate constant of self-catalyzed hydrolytic degradation. In fact, the logarithmic format of molecular weight variation can cover the auto catalyst effect in the kinetic of reaction by more rapid reduction in molecular weight [36].

The variation of number average molecular weight versus time is demonstrated in Figure 9. These experimental data were fitted using Equations (5) and (6) (data are not shown here). High correlation coefficients were not obtained for these fittings. However, the correlation coefficient for Equation (6) was higher and more acceptable. The main reason for deviation from this model is simultaneously crosslinking reactions that led to consuming of high molecular grafted chains.

Temperature is a parameter affecting hydrolytic degradation. According to the literature, at higher temperature the degradation is accomplished with higher speed and usually is fitted better by autocatalytic model. At higher temperature, above $T_{\mathrm{g}}$, movement of water molecules between polymer chains is 


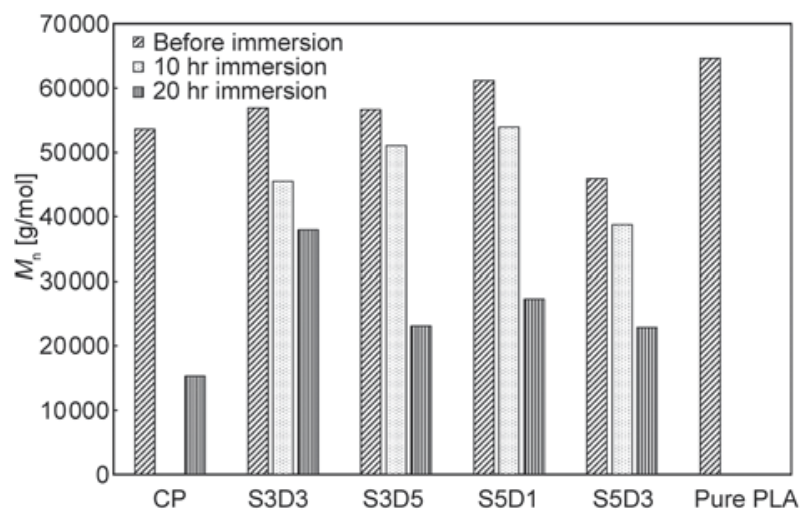

Figure 9. Number-average molecular weight of sol fraction for polymer samples. Samples without immersion in water and after 10 and $20 \mathrm{hr}$ immersion in hot water during crosslinking are illustrated.

facilitated. In our case, crosslinking bonds limit this movement and prevents further degradation. The highest reduction of $M_{\mathrm{n}}$ in CP sample without crosslinking can be a witness for this phenomenon. The presence of low molecular weight PLA as a production of hydrolytic degradation was checked by TGA test and the obtained results (TGA and DTG thermograms) are shown in Figure 10. Although there are no significant differences among the samples in TGA thermograms, a shoulder at lower temperature beside the main peaks are detectable in DTG curves. This shoulder in range of $300-350^{\circ} \mathrm{C}$ is related to the thermal degradation of lower molecular weight oligomers as products of hydrolytic degradation during crosslinking. As mentioned in other reports, the main thermal decomposition is occurred in the range of $300-390^{\circ} \mathrm{C}$ [37]. As can be seen in TGA of treated samples at lower temperature (magnified in Figure 10a), a bit weight loss occurred until $200^{\circ} \mathrm{C}$ related to lactic acid thermal degradation. This monomer is the main product of PLA chain scission.

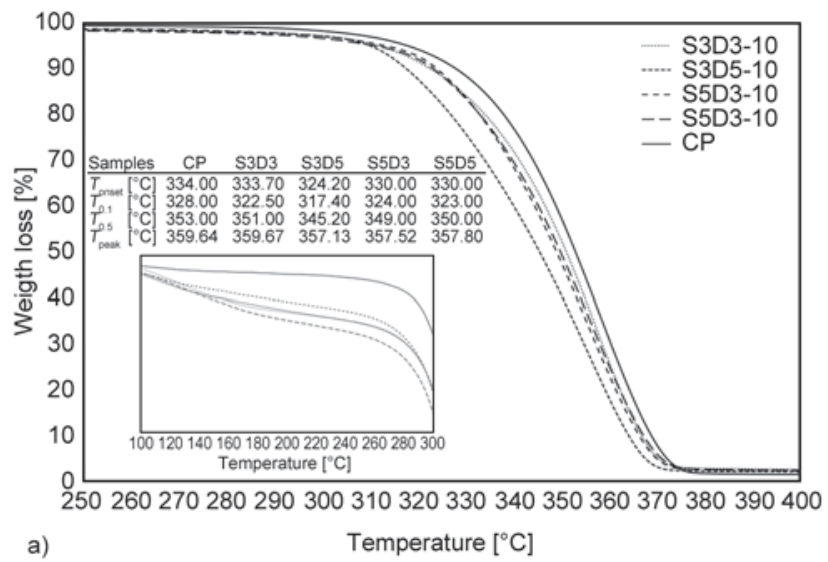

According to Figure 10a (and internal table), the onset temperatures for degradation of treated PLA are clearly lower than that of the CP sample. In the untreated sample, 10 and $50 \%$ of decomposition occurred at about 328 and $353^{\circ} \mathrm{C}$, respectively, and all treated samples showed lower thermal stability and degraded at lower temperatures. In the DTG curves, one can clearly observe the degradation reactions at lower temperatures, as suggested by the shoulder between 300 and $350^{\circ} \mathrm{C}$. The place of shoulder is affected by the competition between crosslinking and hydrolytic degradation and DCP concentration. In other words, when the hydrolytic degradation is the dominant mechanism, the shoulder appeared at lower temperature. On the other hand, the higher concentration of DCP which have not reacted in silane grafting caused in chain scission of PLA, and subsequently to formation of higher concentration of low molecular weight chains.

The results $\left(T_{\text {onset }}\right)$ in embedded table in Figure 10a imply a reduction in thermal stability of the crosslinked samples in comparison to CP sample which is not common. Han et al. [11] reported an increase of thermal stability for silane crosslinking of PLA. The main reason for the contradictory results is the difference in crosslinking temperature. Higher temperature of crosslinking in our study $\left(70^{\circ} \mathrm{C}\right)$, compared to Han's work $\left(40^{\circ} \mathrm{C}\right)$, caused more hydrolytic degradation than crosslinking.

\section{Conclusions}

This work is motivated by current researches in the development of PLA applications as a biodegradable polymer. Silane crosslinking was considered for the improvement of mechanical properties of PLA. Hydrolytic degradation is inevitable during

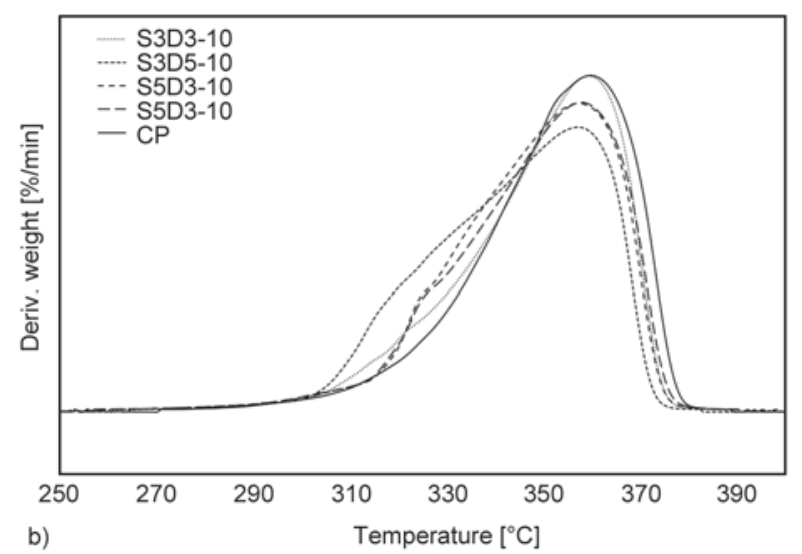

Figure 10. a) TGA and b) DTG diagrams for different PLA samples 
crosslinking by immersion in hot water and appears as a competitive reaction in this method. Two reactions were tracked and the following results can be drawn from this study:

- Hydrolytic degradation was monitored using GPC, TGA, gel content and swelling tests and its negative effect on the crosslinking reaction and obtained gel structure was tracked.

- Silane grafting of PLA was directly affected by silane and peroxide concentrations. Lower concentrations of DCP lead to insufficient radical formation on PLA chains, and consequently low degree of grafting on PLA. On the other hand, samples containing higher DCP content in presence of VTMO silane lead to premature gel formation during grafting reaction.

- Both tight and loose gel structures were found using swelling. The formation of loose gel structure (as a defect) may be attributed to high hydrolytic degradation.

- An extra peak was observed in GPC curve for the grafted samples which implies the formation of higher molecular weight chains due to the grafting reaction. This peak diminished at longer time of immersion in hot water as a result of consumption of grafted PLA molecules in crosslinking reaction.

- Hydrolytic degradation process was intensified at longer crosslinking time and its trace was observed by a peak at lower molecular weights in GPC chromatograms. The low molecular weight oligomers after hydrolytic degradation was also observed in DTG as a shoulder in lower temperature.

- The observations were confirmed with TGA test. The low molecular weight oligomers after hydrolytic degradation observed in DTG as shoulder in lower temperature.

\section{References}

[1] Cairncross R. A., Becker J. G., Ramaswamy S., O'Connor R.: Moisture sorption, transport, and hydrolytic degradation in polylactide. Applied Biochemistry and Biotechnology, 131, 774-785 (2006).

DOI: $10.1385 / A B A B: 131: 1: 774$

[2] Liu M., Yin Y., Fan Z., Zheng X., Shen S., Deng P., Zheng C., Teng H., Zhang W.: The effects of gammairradiation on the structure, thermal resistance and mechanical properties of the PLA/EVOH blends. Nuclear Instruments and Methods in Physics Research Section B: Beam Interactions with Materials and Atoms, 274, 139-144 (2012).

DOI: $10.1016 /$ j.nimb.2011.12.020
[3] Nampoothiri K. M., Nair N. R., John R. P.: An overview of the recent developments in polylactide (PLA) research. Bioresource Technology, 101, 84938501 (2010). DOI: 10.1016/j.biortech.2010.05.092

[4] Xiao L., Wang B., Yang G., Gauthier M.: Poly(lactic acid)-based biomaterials: Synthesis, modification and applications. in 'Biomedical science, engineering and technology' (ed.: Ghista D. N.) InTech, Rijeka, 247282 (2012).

DOI: $10.5772 / 23927$

[5] Wang Y., Chiao S. M., Hung T-F., Yang S-Y.: Improvement in toughness and heat resistance of poly(lactic acid)/polycarbonate blend through twin-screw blending: Influence of compatibilizer type. Journal of Applied Polymer Science, 125, E402-E412 (2012).

DOI: $10.1002 /$ app.36920

[6] Nagasawa N., Kaneda A., Kanazawa S., Yagi T., Mitomo H., Yoshii F., Tamada M.: Application of poly (lactic acid) modified by radiation crosslinking. Nuclear Instruments and Methods in Physics Research Section B: Beam Interactions with Materials and Atoms, 236, 611-616 (2005).

DOI: $10.1016 / \mathrm{j} . n i m b .2005 .04 .052$

[7] He C., Feng W., Cao L., Fan L.: Crosslinking of poly(L-lactide) nanofibers with triallyl isocyanutrate by gamma-irradiation for tissue engineering application. Journal of Biomedical Materials Research Part A, 99, 655-665 (2011).

DOI: $10.1002 / \mathrm{jbm} . \mathrm{a} .33235$

[8] Jin F., Hyon S-H., Iwata H., Tsutsumi S.: Crosslinking of poly(L-lactide) by $\gamma$-irradiation. Macromolecular Rapid Communications, 23, 909-912 (2002).

DOI: 10.1002/1521-3927(20021001)23:15<909::AIDMARC909>3.0.CO;2-8

[9] Malinowski R., Rytlewski P., Żenkiewicz M.: Effects of electron radiation on properties of PLA. Archives of Materials Science and Engineering, 49, 25-39 (2011).

[10] Mitomo H., Kaneda A., Quynh T. M., Nagasawa N., Yoshii F.: Improvement of heat stability of poly(L-lactic acid) by radiation-induced crosslinking. Polymer, 46, 4695-4703 (2005).

DOI: $10.1016 /$ j.polymer.2005.03.088

[11] Han C., Bian J., Liu H., Han L., Wang S., Dong L., Chen S.: An investigation of the effect of silane watercrosslinking on the properties of poly(L-lactide). Polymer International, 59, 695-703 (2010).

DOI: $10.1002 /$ pi. 2760

[12] Takamura M., Nakamura T., Kawaguchi S., Takahashi T., Koyama K.: Molecular characterization and crystallization behavior of peroxide-induced slightly crosslinked poly(L-lactide) during extrusion. Polymer Journal, 42, 600-608 (2010).

DOI: $10.1038 /$ pj.2010.42 
[13] Takamura M., Nakamura T., Takahashi T., Koyama K.: Effect of type of peroxide on cross-linking of poly(Llactide). Polymer Degradation and Stability, 93, 19091916 (2008).

DOI: 10.1016/j.polymdegradstab.2008.07.001

[14] Yang S-L., Wu Z-H., Yang W., Yang M-B.: Thermal and mechanical properties of chemical crosslinked polylactide (PLA). Polymer Testing, 27, 957-963 (2008). DOI: 10.1016/j.polymertesting.2008.08.009

[15] Shayan M., Azizi H., Ghasemi I., Karrabi M.: Effect of modified starch and nanoclay particles on biodegradability and mechanical properties of cross-linked poly lactic acid. Carbohydrate Polymers, 124, 237-244 (2015).

DOI: 10.1016/j.carbpol.2015.02.001

[16] Morshedian J., Hoseinpour P. M.: Polyethylene crosslinking by two-step silane method: A review. Iranian Polymer Journal, 18, 103-128 (2009).

[17] Azizi H., Morshedian J., Barikani M.: Silane grafting and moisture crosslinking of polyethylene: The effect of molecular structure. Journal of Vinyl and Additive Technology, 15, 184-190 (2009).

DOI: $10.1002 / \mathrm{vnl} .20194$

[18] Barzin J., Azizi H., Morshedian J.: Preparation of silanegrafted and moisture cross-linked low density polyethylene: Part I: Factors affecting performance of grafting and cross-linking. Polymer-Plastics Technology and Engineering, 45, 979-983 (2006).

DOI: 10.1080/03602550600718209

[19] Barzin J., Azizi H., Morshedian J.: Preparation of silanegrafted and moisture crosslinked low density polyethylene. Part II: Electrical, thermal and mechanical properties. Polymer-Plastics Technology and Engineering, 46, 305-310 (2007).

DOI: $10.1080 / 03602550601155815$

[20] Żenkiewicz M., Malinowski R., Rytlewski P., Richert A., Sikorska W., Krasowska K.: Some composting and biodegradation effects of physically or chemically crosslinked poly(lactic acid). Polymer Testing, 31, 83-92 (2011).

DOI: $10.1016 /$ j.polymertesting.2011.09.012

[21] Hakkarainen M.: Aliphatic polyesters: Abiotic and biotic degradation and degradation products. Degradable aliphatic polyesters, 157, 113-138 (2002).

DOI: $10.1007 / 3-540-45734-84$

[22] Hurrell S., Cameron R. E.: The effect of initial polymer morphology on the degradation and drug release from polyglycolide. Biomaterials, 23, 2401-2409 (2002). DOI: 10.1016/S0142-9612(01)00376-3

[23] Grizzi I., Garreau H., Li S., Vert M.: Hydrolytic degradation of devices based on poly(DL-lactic acid) sizedependence. Biomaterials, 16, 305-311 (1995). DOI: $10.1016 / 0142-9612(95) 93258-\mathrm{F}$

[24] Hyon S. H., Jamshidi K., Ikada Y.: Effects of residual monomer on the degradation of DL-lactide polymer. Polymer International, 46, 196-202 (1998).

DOI: 10.1002/(SICI)1097-0126(199807)46:3<196:: AID-PI914>3.0.CO;2-Y
[25] Tsuji H., Miyauchi S.: Poly(L-lactide): VI Effects of crystallinity on enzymatic hydrolysis of poly(L-lactide) without free amorphous region. Polymer Degradation and Stability, 71, 415-424 (2001). DOI: 10.1016/S0141-3910(00)00191-9

[26] Zhou Q., Xanthos M.: Nanoclay and crystallinity effects on the hydrolytic degradation of polylactides. Polymer Degradation and Stability, 93, 1450-1459 (2008).

DOI: 10.1016/j.polymdegradstab.2008.05.014

[27] Weir N. A., Buchanan F. J., Orr J. F., Farrar D. F., Dickson G. R.: Degradation of poly-L-lactide. Part 2: Increased temperature accelerated degradation. Journal of Engineering in Medicine, 218, 321-330 (2004). DOI: $10.1243 / 0954411041932809$

[28] Paul M-A., Delcourt C., Alexandre M., Degée P., Monteverde F., Dubois P.: Polylactide/montmorillonite nanocomposites: Study of the hydrolytic degradation. Polymer Degradation and Stability, 87, 535-542 (2005). DOI: $10.1016 /$ j.polymdegradstab.2004.10.011

[29] Mitomo H., Kaneda A., Quynh T.M., Nagasawa N., Yoshii F.: Improvement of heat stability of poly (L-lactic acid) by radiation-induced crosslinking. Polymer, 46, 4695-4703 (2005).

DOI: $10.1016 /$ j.polymer.2005.03.088

[30] Södergård A., Selin J. F., Näsman J. H.: Hydrolytic degradation of peroxide modified poly(L-lactide). Polymer Degradation and Stability, 51, 351-359 (1996). DOI: 10.1016/0141-3910(95)00271-5

[31] Sperling L. H.: Introduction to physical polymer science. Wiley, Hoboken (2005).

[32] Liu N. C., Yao G. P., Huang H.: Influences of grafting formulations and processing conditions on properties of silane grafted moisture crosslinked polypropylenes. Polymer, 41, 4537-4542 (2000). DOI: $10.1016 / \mathrm{S} 0032-3861(99) 00654-0$

[33] Nijenhuis A. J., Grijpma D. W., Pennings A. J.: Crosslinked poly(L-lactide) and poly( $\varepsilon$-caprolactone). Polymer, 37, 2783-2791 (1996). DOI: 10.1016/0032-3861(96)87642-7

[34] Liu J., Lou L., Yu W., Liao R., Li R., Zhou C.: Long chain branching polylactide: Structures and properties. Polymer, 51, 5186-5197 (2010).

DOI: $10.1016 /$ j.polymer.2010.09.002

[35] Pistner H., Bendix D. R., Mühling J., Reuther J. F.: Poly(L-lactide): A long-term degradation study in vivo: Part III. Analytical characterization. Biomaterials, 14, 291-298 (1993).

DOI: 10.1016/0142-9612(93)90121-H

[36] Pitt C. G., Zhong-wei G.: Modification of the rates of chain cleavage of poly( $\varepsilon$-caprolactone) and related polyesters in the solid state. Journal of Controlled Release, 4, 283-292 (1987).

DOI: 10.1016/0168-3659(87)90020-4

[37] Feng L., Li G., Bian X., Chen Z., Liu Y., Cui Y., Chen $\mathrm{X}$.: Rapid determination of residual monomer in polylactide using thermogravimetric analysis. Polymer Testing, 31, 660-662 (2012).

DOI: 10.1016/j.polymertesting.2012.03.010 